\title{
ORIGINAL ARTICLE Estimating the glomerular filtration rate using serum cystatin C levels in patients with spinal cord injuries
}

\author{
EJ Erlandsen ${ }^{1}, \mathrm{RM}$ Hansen $^{2}, \mathrm{E} \mathrm{Randers}^{3}$, LE Petersen ${ }^{4}, \mathrm{~J}_{\text {Abrahamsen }}{ }^{4}$ and IL Johannesen ${ }^{2}$
}

\begin{abstract}
Study design: Prospective cohort study.
Objectives: To investigate the relationship between ${ }^{51}$ chromium-ethylene-diamine-tetra-acetate $\left({ }^{51} \mathrm{Cr}\right.$-EDTA) clearance, serum cystatin C (CysC), serum creatinine, creatinine clearance and estimated glomerular filtration rate (eGFR $\mathrm{MDRD}_{\mathrm{MDR}}$, MDR stands for modification of diet in renal disease) based on the serum creatinine in patients with complete or incomplete spinal cord injury (SCI) and to develop and evaluate a GFR-estimating equation using serum CysC.
\end{abstract}

Settings: Spinal Cord Injury Unit, Viborg Regional Hospital, Viborg, Denmark.

Methods: Ninety-eight men and 47 women with SCl were included in the study. Serum CysC levels were measured by an automated particle-enhanced nephelometric immunoassay, serum and urine creatinine levels were measured by an enzymatic method traceable to the IDMS creatinine reference method, and ${ }^{51} \mathrm{Cr}$-EDTA clearance was measured by a multiple plasma sample method.

Results: The area under the curves (AUCS) in the non-parametric receiver operating characteristics (ROC) plots for serum CysC were compared with serum creatinine and to eGFR $\mathrm{MDRD}_{\text {and }}$ and revealed a significant difference $(P$-value $<0.05)$ for all SCI patients. There was no significant difference between the AUC for serum CysC compared with the AUC for creatinine clearance. GFR ( $\mathrm{ml} \mathrm{min}^{-1}$ per $1.73 \mathrm{~m}^{2}$ ) can be calculated from serum CysC values $\left(\mathrm{mgl}^{-1}\right)$ using the equation eGFR $\mathrm{CysC}=212 \cdot \exp (0.914 \cdot$ CysC). The model accurately predicted the GFR of $88 \%$ of patients within $\pm 30 \%$ of the measured GFR, and it was able to predict the GFR of $50 \%$ of patients within $\pm 10 \%$ of the measured GFR.

Conclusion: In patients with SCI, GFR can be estimated independent of age, sex and muscle mass by a newly developed equation based on a single serum CysC value.

Spinal Cord (2012) 50, 778-783; doi:10.1038/sc.2012.52; published online 1 May 2012

Keywords: creatinine; creatinine clearance; cystatin C; glomerular filtration rate; kidney function; spinal cord injury

\section{INTRODUCTION}

Patients with spinal cord injuries (SCIs) are at increased risk of developing renal insufficiency, and these patient needs to have their renal function examined on a regular basis. ${ }^{1}$ The glomerular filtration rate (GFR) is generally considered the best measure of renal function. ${ }^{2}$ Determining the GFR requires the use of invasive techniques to measure the plasma clearance rate of an injected substance exclusively excreted via glomerular filtration, for example, inulin, ${ }^{51}$ chromiumethylene-diamine-tetra-acetate $\quad\left({ }^{51} \mathrm{Cr}-\mathrm{EDTA}\right), \quad{ }^{99 \mathrm{~m}} \mathrm{Tc}-\mathrm{DTPA}, \quad{ }^{125} \mathrm{I}-$ iothalamate or iohexol. ${ }^{2}$ All of these procedures are laboratoryintensive, time consuming, expensive, and not suitable for routine use.

The measurements of serum creatinine and creatinine clearance are used as indirect markers of the GFR. ${ }^{2,3}$ However, the concentration of serum creatinine is not an ideal indicator of GFR, and glomerular filtration is only one of the parameters that determines the serum concentration of creatinine. Renal handling and metabolism, food intake and methodological interference may influence the concentration of serum creatinine. ${ }^{3}$ Creatinine correlates with muscle mass, and patients with spinal cord injuries exhibit rapidly decreasing muscle mass after the injury. Accurately measuring creatinine clearance involves a $24-\mathrm{h}$ urine collection, which is often difficult and time consuming for patients to perform. ${ }^{4}$ In patients with SCIs, urine collection is particularly difficult and often inaccurate, and creatinine clearance is encumbered with some uncertainties. $^{5,6}$

There have been several attempts to construct equations to predict GFR based on the serum creatinine and additional parameters. ${ }^{7}$ For adults, the most accepted and widely used GFR prediction equation is that proposed by the modification of diet in renal disease (MDRD), which reports relative GFR values in $\mathrm{ml} \mathrm{min}^{-1}$ per $1.73 \mathrm{~m}^{2} .2,8$

Cystatin C (CysC) is a new promising marker of GFR. ${ }^{9,10} \mathrm{CysC}$ is a non-glycosylated, low molecular weight protein $\left(\mathrm{M}_{\mathrm{r}}=13359 \mathrm{Da}\right)$. It is produced by all nucleated cells at a constant rate, freely filtered in the glomeruli and reabsorbed and catabolised in the proximal tubular cells. $^{9,10}$ The characteristics of CysC indicate that its serum concentration is largely determined by GFR, thus making CysC an endogenous indicator of GFR. CysC levels are independent of gender, age $\left(>1\right.$ year) and muscle mass. ${ }^{9,10}$

The aim of this prospective study was to investigate the relationship between ${ }^{51} \mathrm{Cr}$-EDTA clearance (gold standard for GFR), serum CysC, serum creatinine, creatinine clearance and $\mathrm{eGFR}_{\mathrm{MDRD}}$ in a large cohort of patients with complete and incomplete spinal cord injuries and to develop and evaluate a GFR-estimating equation using serum CysC.

${ }^{1}$ Department of Clinical Biochemistry, Viborg Regional Hospital, Viborg, Denmark; ${ }^{2}$ Department of Spinal Cord Injury, Viborg Regional Hospital, Viborg, Denmark; ${ }^{3}$ Department of Internal Medicine, Viborg Regional Hospital, Viborg, Denmark and ${ }^{4}$ Department of Clinical Physiology, Viborg Regional Hospital, Viborg, Denmark 


\section{MATERIALS AND METHODS}

\section{Patients}

One hundred and forty-five patients ( 98 men and 47 women) between the ages of 11.3 and 82.4 years with SCIs classified as the American Spinal Injury Association (ASIA) Impairment Scale (AIS) A-D were included in the study.

The local committee of ethics approved the study protocol according to the Helsinki declaration, and all of the patients gave their written informed consent before the start of the study.

\section{Procedure}

During a 4-year period from November 2004 to November 2008, patients were admitted at the Spinal Cord Unit at the Viborg Regional Hospital. Blood samples were drawn to analyse serum $\mathrm{CysC}$ and creatinine levels. A 24-h urine was collected for the determination of creatinine clearance. ${ }^{51}$ Cr-EDTA clearance was measured at the Department of Clinical Physiology.

\section{Analytical methods}

The blood samples were centrifuged at $2000 \mathrm{~g}$ for $12 \mathrm{~min}$. Serum was isolated and analysed on the same day. The serum CysC levels were analysed using the Siemens N Latex CysC assay on the Dade Behring Nephelometer II (Siemens Diagnostics, Marburg, Germany). ${ }^{11}$ The method was a fully automated particle-enhanced nephelometric immunoassay. The serum and urine creatinine levels were analysed by an enzymatic method traceable to the IDMS creatinine reference method on Modular P (Roche Diagnostics, Mannheim, Germany).

GFR was measured using a single injection technique with a ${ }^{51} \mathrm{Cr}$-EDTA complex by a multiple plasma sample method. ${ }^{12}$

The estimated GFR $_{\text {MDRD }}$ was calculated using the equation developed from the MDRD study. ${ }^{8}$ Creatinine clearance and ${ }^{51} \mathrm{Cr}$-EDTA clearance was adjusted to a body surface area of $1.73 \mathrm{~m}^{2}$.

\section{GFR prediction model based on serum CysC}

Initially, linear stepwise regression was used to test the relationship between the measured GFR and the independent variables of the serum CysC level, serum creatinine level, sex, age, height, weight, body surface area, and body mass index. This analysis indicated that the measured GFR was dependent on only the serum $\mathrm{CysC}$ value and was independent of the other variables tested in the study. For this reason, only models that included the variable serum CysC levels were tested.

Based on the hypothesis that GFR values can be calculated from the CysC values by the equation $\mathrm{GFFR}_{\mathrm{Cys}}=A \times \exp \left(-k^{\star} \mathrm{Cys} \mathrm{C}\right)$, the constants $A$ and $k$ were determined as those values, which made the sum over all measured values

$$
\mathrm{GFR}_{\text {mea }} ; \sum_{\text {All measured values }} \frac{\left|\mathrm{GFR}_{\text {mea }}-\mathrm{GFR}_{\text {cal }}\right|}{\mathrm{GFR}_{\text {mea }}}
$$

as small as possible.

$\mathrm{GFR}_{\text {mea }}=$ measured GFR.

This method is superior to the ordinary exponential regression using weighted regression.

\section{Statistical analysis}

The statistical analysis was performed using the Student Edition of statistic version 2.0 (Analytical Software, Tallahassee, FL, USA), GraphPad Prism version 4.00 for Windows (GraphPad Software, San Diego, CA, USA), and Excel 2010 (Microsoft Corporation, Redmond, WA, USA). Data are expressed as mean values \pm s.d. A $P$-value $<0.05$ was considered significant. ROC plots were constructed using GraphPad Prism and GraphROC for Windows version 2.0.

\section{RESULTS}

\section{The study population}

The characteristics of the study population are shown in Table 1. Each value is reported as the mean \pm s.d. The patients' characteristics according to the AIS impairment scale are shown in Table 2. Thirtynine per cent of the patients (57 patients) with SCIs were complete

Table 2 Patient characteristics according to the American Spinal Injury Association Impairment Scale

\begin{tabular}{rrrr}
\hline & Men & Women & All patients \\
\hline Complete & 47 & 10 & 57 \\
AIS A & 47 & 10 & 57 \\
Incomplete & 51 & 37 & 88 \\
AIS B & 4 & 6 & 10 \\
AIS C & 29 & 16 & 45 \\
AIS D & 18 & 15 & 33
\end{tabular}

Abbreviation: AIS, American Spinal Injury Association Impairment Scale.

Table 1 Characteristics of patients with spinal cord injuries (mean \pm s.d.)

\begin{tabular}{|c|c|c|c|}
\hline & Men & Women & All patients \\
\hline Number & 98 & 47 & 145 \\
\hline Age (year) & $47.1 \pm 16.4$ & $50.8 \pm 16.5$ & $48.3 \pm 16.5$ \\
\hline Height (m) & $1.80 \pm 0.07$ & $1.68 \pm 0.07$ & $1.76 \pm 0.09$ \\
\hline Weight (kg) & $79.4 \pm 16.9$ & $68.6 \pm 18.0$ & $75.9 \pm 18.0$ \\
\hline Body surface area $\left(\mathrm{m}^{2}\right)$ & $1.98 \pm 0.19$ & $1.77 \pm 0.22$ & $1.91 \pm 0.22$ \\
\hline Body mass index $\left(\mathrm{kg} \mathrm{m}^{-2}\right)$ & $24.5 \pm 5.0$ & $24.1 \pm 5.5$ & $24.4 \pm 5.1$ \\
\hline Age of injury (year) & $2.5 \pm 6.6$ & $2.3 \pm 6.7$ & $2.5 \pm 6.6$ \\
\hline Serum cystatin $\mathrm{C}\left(\mathrm{mgl}^{-1}\right)$ & $1.08 \pm 0.41$ & $1.05 \pm 0.37$ & $1.07 \pm 0.39$ \\
\hline Serum creatinine $\left(\mu \mathrm{moll}^{-1}\right)$ & $68 \pm 22$ & $56 \pm 15$ & $64 \pm 21$ \\
\hline 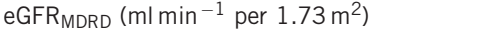 & $120.0 \pm 36.8$ & $114.8 \pm 53.6$ & $118.3 \pm 42.9$ \\
\hline Creatinine clearance $\left(\mathrm{ml} \mathrm{min}^{-1}\right.$ per $\left.1.73 \mathrm{~m}^{2}\right)$ & $94.2 \pm 25.1$ & $86.5 \pm 27.7$ & $91.7 \pm 26.1$ \\
\hline${ }^{51} \mathrm{Cr}$-EDTA clearance $\left(\mathrm{ml} \mathrm{min}^{-1}\right.$ per $\left.1.73 \mathrm{~m}^{2}\right)$ & $87.4 \pm 23.2$ & $84.3 \pm 21.6$ & $86.4 \pm 22.7$ \\
\hline  & $83.2 \pm 20.1$ & $84.7 \pm 19.3$ & $83.7 \pm 19.8$ \\
\hline
\end{tabular}


injuries (AIS A) and 61 per cent (88 patients) were incomplete injuries (AIS B-D).

Relationship between ${ }^{51}$ Cr-EDTA clearance (GFR), CysC levels, creatinine levels, creatinine clearance and eGFR $_{M D R D}$

Figure 1 illustrates the relationship between ${ }^{51} \mathrm{Cr}$-EDTA clearance, CysC levels, creatinine levels, creatinine clearance and eGFR $_{M D R D}$ in patients with complete SCIs ( $a, c$, e and g) and incomplete SCIs (b, d, $\mathrm{f}$ and $\mathrm{h}$ ). The vertical lines at 90, 60, 30 and $15 \mathrm{ml} \mathrm{min}^{-1}$ per $1.73 \mathrm{~m}^{2}$ indicate the GFR cutoff values for stage I through stage V kidney disease according to the K/DOIQ classification guidelines. ${ }^{13}$ The upper reference interval for CysC levels is indicated by a solid horizontal line at $1.02 \mathrm{mgl}^{-1}$ in Figure $1 \mathrm{a}$ and $b{ }^{14}$ The upper reference intervals for creatinine levels are indicated in Figure 1c and $\mathrm{d}$ by a solid horizontal line for men at $105 \mu \mathrm{moll}^{-1}$ and a dotted horizontal line for women at $90 \mu \mathrm{moll}^{-1}{ }^{15}$ For creatinine clearance
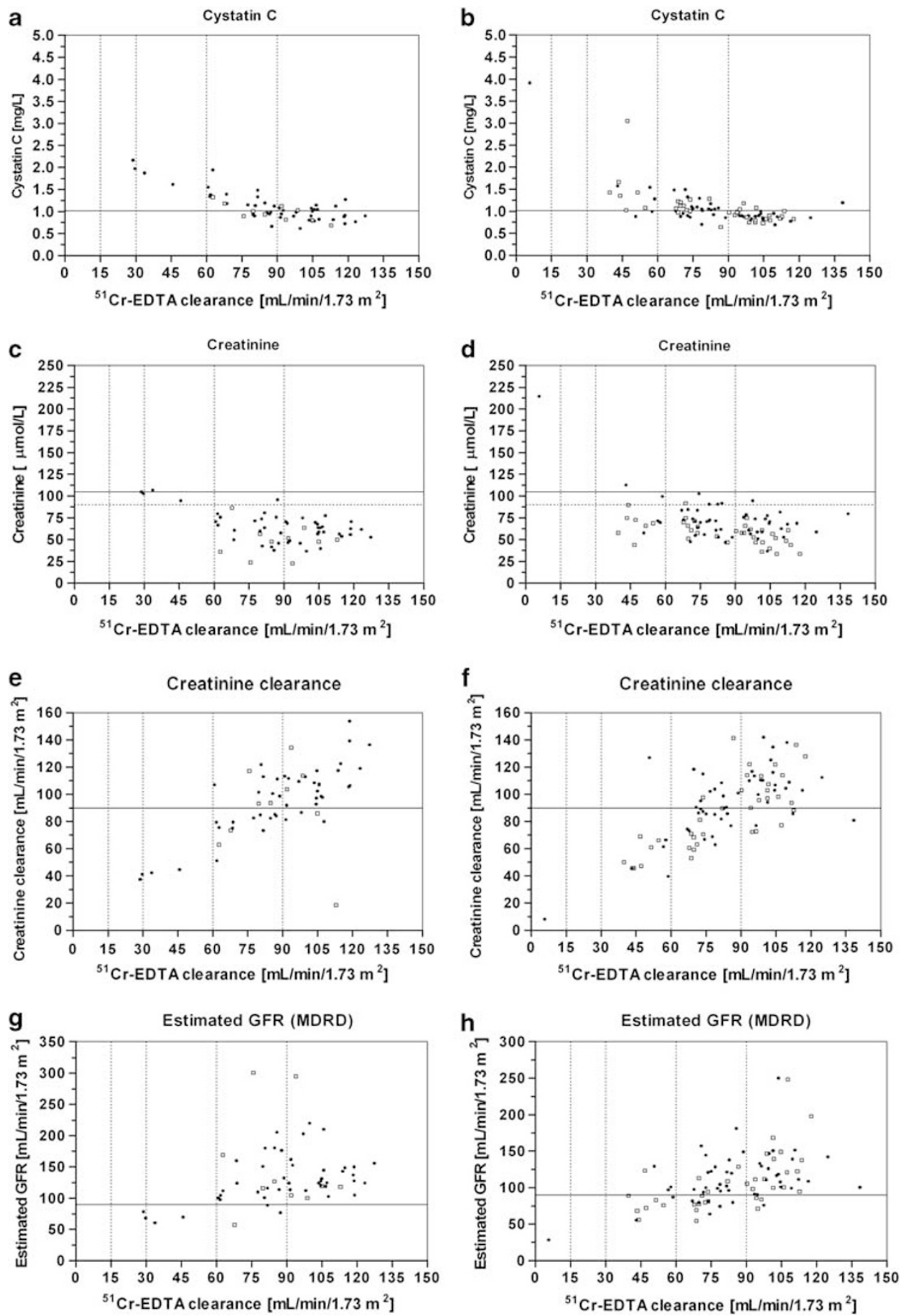

Figure 1 Relationship between ${ }^{51} \mathrm{Cr}$-EDTA clearance, cystatin C levels, creatinine levels, creatinine clearance and estimated GFR (MDRD). Men ( $)$ and women (O). (a, c, e, g) Patients with complete SCls. (b, d, f, h) Patients with incomplete SCls. The vertical lines at $90,60,30$ and $15 \mathrm{ml}^{-1} \mathrm{~min}^{-1}$ per $1.73 \mathrm{~m}^{2}$ indicate the GFR cutoff values for stage I to stage $V$ kidney disease according to the K/DOIQ classification guidelines. ${ }^{13}$ 
Table 3 Patient characteristics according to K/DOQI guideline ${ }^{13}$ for kidney function according to GFR

\begin{tabular}{|c|c|c|c|c|}
\hline \multicolumn{2}{|c|}{ GFR $\left(\mathrm{m} / \mathrm{min}^{-1}\right.$ per $\left.1.73 \mathrm{~m}^{2}\right)$} & \multirow{2}{*}{$\frac{M e n}{46}$} & \multirow{2}{*}{$\begin{array}{c}\text { Women } \\
24\end{array}$} & \multirow{2}{*}{$\frac{\text { All patients }}{70}$} \\
\hline Stage I & $>90$ & & & \\
\hline Stage II & $60-89$ & 42 & 16 & 58 \\
\hline Stage III & $30-59$ & 8 & 7 & 15 \\
\hline Stage IV & $15-29$ & 1 & 0 & 1 \\
\hline Stage V & $<15$ & 1 & 0 & 1 \\
\hline
\end{tabular}

Abbreviation: GFR, glomerular filtration rate.

GFR: ${ }^{51} \mathrm{Cr}$-EDTA clearance.

Table 4 Area under the curve (AUC) and s.e. of non-parametric ROC plots for cystatin C, creatinine, creatinine clearance, eGFR $\mathrm{MDRD}_{\text {and }}$ eGFR CysC $_{\text {C }}$

\begin{tabular}{|c|c|c|c|}
\hline & $\begin{array}{c}\text { All SCl patients } \\
(\mathrm{n}=145) \\
\text { AUC } \pm \text { s.e. }\end{array}$ & $\begin{array}{c}\text { Complete SCl } \\
(\mathrm{n}=57) \\
\text { AUC } \pm \text { s.e. }\end{array}$ & $\begin{array}{c}\text { Incomplete SCl } \\
(\mathrm{n}=88) \\
\text { AUC+s.e. }\end{array}$ \\
\hline Serum cystatin C & $0.830 \pm 0.034$ & $0.825 \pm 0.056$ & $0.850 \pm 0.042$ \\
\hline Serum creatinine & $0.668 \pm 0.045$ & $0.635 \pm 0.079$ & $0.672 \pm 0.058$ \\
\hline Creatinine clearance & $0.815 \pm 0.036$ & $0.789 \pm 0.061$ & $0.834 \pm 0.043$ \\
\hline $\mathrm{eGFR}_{\mathrm{MDRD}}$ & $0.709 \pm 0.043$ & $0.653 \pm 0.078$ & $0.728 \pm 0.053$ \\
\hline $\mathrm{eGFR}_{\text {CysC }}$ & $0.830 \pm 0.034$ & $0.825 \pm 0.056$ & $0.850 \pm 0.042$ \\
\hline
\end{tabular}

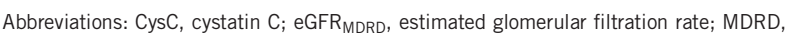
modification of diet in renal disease; $\mathrm{ROC}$, receiver operating characteristics; $\mathrm{SCl}$, spinal cord injury.

GFR ( ${ }^{51} \mathrm{Cr}$-EDTA clearance) cutoff value was set at $90 \mathrm{ml} \mathrm{min}^{-1}$ per $1.73 \mathrm{~m}^{2}$

(Figure 1e and $\mathrm{f}$ ) and for estimated GFR (Figure $1 \mathrm{~g}$ and $\mathrm{h}$ ), the upper reference intervals are indicated by a horizontal line at $90 \mathrm{ml} \mathrm{min}^{-1}$ per $1.73 \mathrm{~m}^{2}$. Table 3 displays the patient characteristics according to the GRF cutoff values for stage I to stage V kidney disease according to the K/DOIQ classification guidelines. ${ }^{13}$ Forty-eight per cent of the patients (70 patients) were classified as Stage I and 40 per cent of the patients (58 patients) were classified as stage II. Twelve per cent of the patients (17 patients) were classified as stage III to stage V.

Table 4 shows the area under the curve (AUC) of the nonparametric ROC plots for the serum CysC levels, serum creatinine levels, creatinine clearance, eGFR $\mathrm{MDRD}_{\mathrm{D}}$ and $\mathrm{eGFR}_{\mathrm{CysC}}$ using a GFR cutoff value of $90 \mathrm{ml} \mathrm{min}^{-1}$ per $1.73 \mathrm{~m}^{2}$. A comparison of the AUC for serum CysC levels with the AUC for serum creatinine levels as well as a comparison with the AUC for estimated GFR $_{M D R D}$ revealed a significant difference $(P$-value $<0.05)$ for all patients with SCIs $(n=145)$, for patients with complete SCIs $(n=57)$ and for patients with incomplete SCIs $(n=88)$. There was no significant difference between the AUC for serum CysC levels and $\mathrm{eGFR}_{\mathrm{CysC}}$ compared with the AUC for creatinine clearance.

\section{GFR prediction model based on serum CysC}

The estimated $\mathrm{GFR}_{\mathrm{CysC}}\left(\mathrm{ml} \mathrm{min}{ }^{-1}\right.$ per $\left.1.73 \mathrm{~m}^{2}\right)$ can be calculated from the serum CysC values $\left(\mathrm{mgl}^{-1}\right)$ using the equation $\mathrm{eGFR}_{\mathrm{Cys}}=212 \cdot \exp (-0.914 \cdot \mathrm{CyC})$, an equation that was determined using the data from patients with complete and incomplete SCIs as shown in Table 5. The corresponding equations for patients with complete and incomplete SCIs are also shown in Table 5. The curves for the prediction models are shown in Figure $2 \mathrm{a}-\mathrm{c}$. The difference plot of the measured GFRs versus the difference between the measured GFR minus the eGFR $\mathrm{CysC}_{\mathrm{C}}$ are shown in Figure $2 \mathrm{~d}-\mathrm{f}$. The model was accurate within $\pm 50 \%$ of the reference method in $98 \%$ of
Table 5 Equations for estimation of GFR based on serum cystatin C, and deviation of estimated values of eGFR $\mathrm{CysC}_{\mathrm{C}}$ and $\mathrm{GGFR}_{\text {MDRD }}$ from measured GFR

\begin{tabular}{|c|c|c|c|c|c|}
\hline \multirow{2}{*}{ Patient group } & \multirow{2}{*}{$\mathrm{n}$} & \multirow{2}{*}{$\begin{array}{c}\text { Equation for eGFR } R_{C y s C} \\
A \cdot \exp (-k \cdot C y s C))\end{array}$} & \multicolumn{3}{|c|}{ Deviation from mGFR less than } \\
\hline & & & $\pm 10 \%$ & $\pm 30 \%$ & $\pm 50 \%$ \\
\hline All patients & 145 & $212 \cdot \exp (-0.914 \cdot$ CysC $)$ & $50 \%$ & $88 \%$ & $98 \%$ \\
\hline Complete SCl & 57 & $221 \cdot \exp (-0.944 \cdot$ CysC $)$ & $49 \%$ & $91 \%$ & $100 \%$ \\
\hline Incomplete SCl & 88 & $206 \cdot \exp (-0.907 \cdot$ CysC $)$ & $50 \%$ & $89 \%$ & $97 \%$ \\
\hline All patients & 145 & $\mathrm{eGFR}_{\mathrm{MDRD}}{ }^{8}$ & $17 \%$ & $52 \%$ & $73 \%$ \\
\hline Complete SCI & 57 & $\mathrm{eGFR}_{\text {MDRD }}{ }^{8}$ & $11 \%$ & $47 \%$ & $61 \%$ \\
\hline Incomplete SCI & 88 & $\mathrm{eGFR}_{\mathrm{MDRD}}{ }^{8}$ & $21 \%$ & $56 \%$ & $76 \%$ \\
\hline
\end{tabular}

Abbreviations: CysC, cystatin C; eGFR $\mathrm{MDRD}$, estimated glomerular filtration rate; mGFR, measured GFR; MDRD, modification of diet in renal disease; SCI, spinal cord injury. The constants $A$ and $k$ calculated according to equation 1 . mGFR: ${ }^{51} \mathrm{Cr}$-EDTA clearance.

patients, accurate within $\pm 30 \%$ of the reference method in $88 \%$ of patients, and accurate within $\pm 10 \%$ of the reference method in $50 \%$ of patients, as shown in Table 5. In comparison, the eGFR $\mathrm{MDRD}$ model was accurate within \pm 50 of the reference method in $73 \%$ of patients, accurate within $\pm 30 \%$ of the reference method in $52 \%$ of the patients and accurate within $\pm 10 \%$ of the reference method in $17 \%$ of the patients, as shown in Table 5 .

\section{DISCUSSION}

The present study including 145 patients is the first large cohort study comparing CysC levels with the ${ }^{51} \mathrm{Cr}$-EDTA clearance, creatinine levels, creatinine clearance and estimated $\mathrm{GFR}_{\mathrm{MDRD}}$ in patients with complete and incomplete SCIs.

The findings in the present study suggest that serum CysC levels are a better index of the renal function than serum creatinine levels or eGFR $_{\text {MDRD }}$ in patients with complete and incomplete SCIs. No significant difference was found between serum CysC levels and creatinine clearance. Furthermore, this study showed that GFR can be estimated by a simple equation based on a single serum $\mathrm{Cys} C$ value.

We have previously described a prospective study enroling 31 patients with spinal cord injuries and demonstrating that CysC levels correlated better with ${ }^{51} \mathrm{Cr}$-EDTA clearance (GFR) than did serum creatinine levels and $\mathrm{eGFR}_{\mathrm{MDRD}}{ }^{16}$ In 23 of the 31 patients, the creatinine clearance was determined, and no significant difference was found between $\mathrm{Cys} C$ levels and creatinine clearance using non-parametric ROC plots. ${ }^{16}$

In the present study, only three serum creatinine values exceeded the upper reference limit for serum creatinine, and $\mathrm{eGFR}_{\mathrm{MDRD}}$ overestimated the GFR by $37 \%$. This finding is consistent with previous studies that also found that serum creatinine levels were not able to detect the early deterioration of renal function ${ }^{1,16}$ and that the eGFR $_{\text {MDRD }}$ equation, ${ }^{5,16,17}$ the Cockcroft-Gault equation ${ }^{1,5,16}$ and the CKD-EPI equation ${ }^{17}$ overestimated the true creatinine clearance and the measured GFR. An empirically derived correction factor of 0.7 for

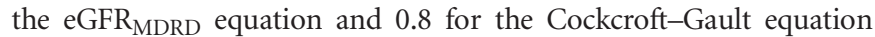
markedly improved the performance and accuracy of both formulas. ${ }^{5}$

A 24-h creatinine clearance measured from collected urine was an acceptable method for measuring GFR in patients with SCIs. ${ }^{1,5,16}$ In contrast to this finding, Sepahpanah et al. ${ }^{6}$ reported significant variation in the serial testing of creatinine clearance and concluded that the test had little value as a screening test for renal disease in patients with SCIs. 

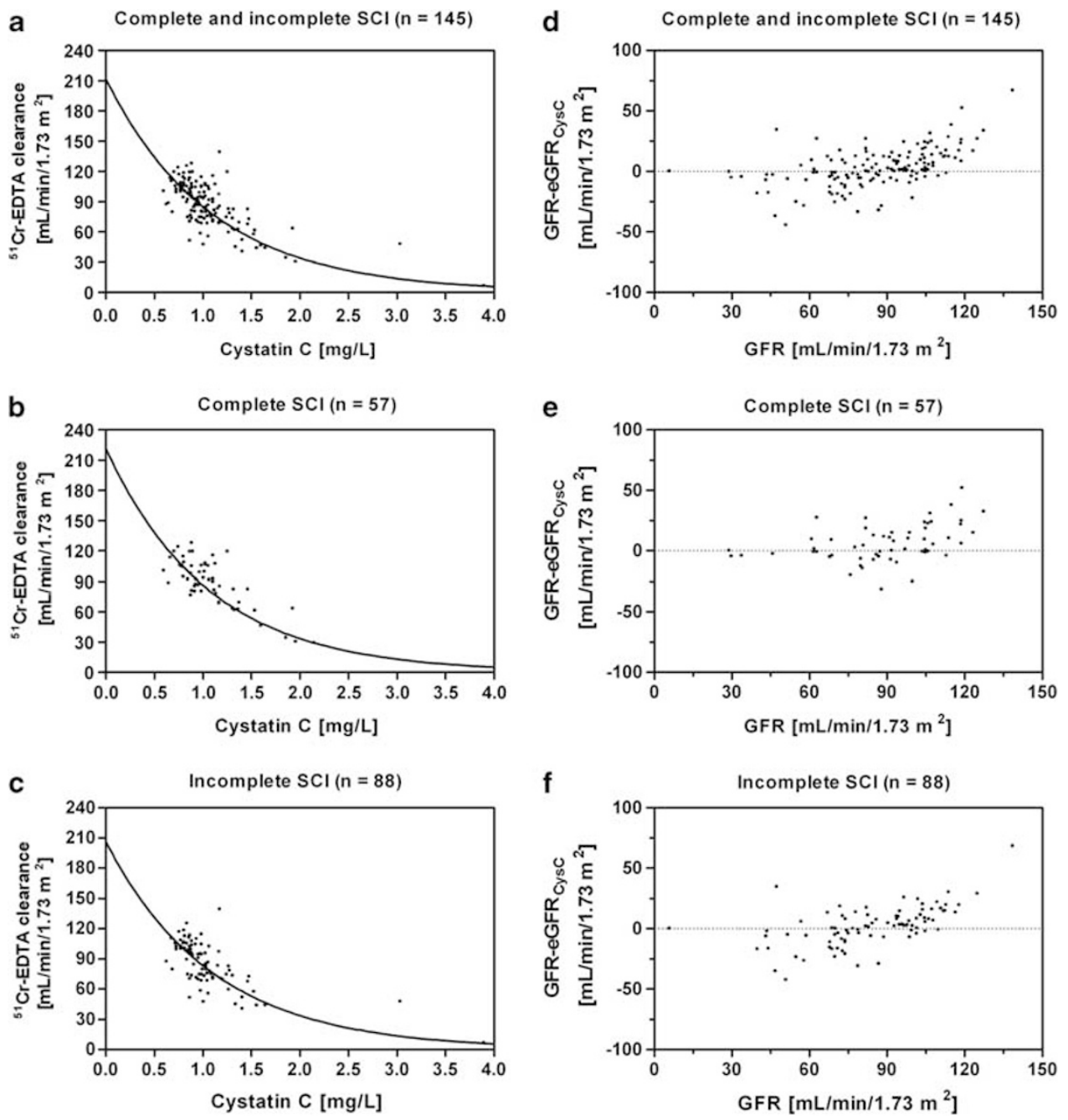

Figure 2 GFR prediction models based on serum cystatin C levels.(a) All patients: eGFR CysC $=212 \cdot \exp (-0.914 \cdot$ CysC), $n=145$. (b) Motor complete patients: $\mathrm{eGFR}_{\mathrm{CysC}}=221 \cdot \exp (-0.944 \cdot \mathrm{CysC}), n=57$. (c) Motor incomplete patients: eGFR $\mathrm{CysC}=206 \cdot \exp (-0.907 \cdot$ CysC), $n=88$. (d-f): Difference plots of the measured GFRs versus the difference between the measured GFRs minus the eGFR $\mathrm{CysC}_{\text {C }}$ corresponding to figure (a), (b) and (c).

In the present study, we have developed separate equations for estimating GFR in patients with complete SCIs, incomplete SCIs and for both groups based on a single serum $\mathrm{Cys} C$ value as shown in Table 5. The equations are independent of sex, age and muscle mass. The differences between the three equations are slight, and we recommend using the equation developed for the whole group of patients with SCIs. As shown in the difference plot in Figure 2, the difference between the measured and the $\mathrm{eGFR}_{\mathrm{Cys}}$ varies closely around zero and is independent of measured GFR.

The advantage of this equation is that it gives the estimated values for GFR whether $\mathrm{CysC}$ is below the reference range $\left(<0.51 \mathrm{mgl}^{-1}\right)$ or close to the border of dialysis $\left(4-5 \mathrm{mgl}^{-1}\right)$, unlike several published formulas for estimating GFR based on CysC levels. ${ }^{18,19}$

Over the last decade, only a few papers have described measuring and estimating the GFR in patients with SCIs. Creatinine levels or creatinine clearance were included in six papers, ${ }^{1,5,6,16,17,20}$ and $\mathrm{CysC}$ levels were included in only two papers. ${ }^{16,20}$

A gold standard for GFR, ${ }^{99}$ Tc-DTPA clearance ${ }^{1}$ or ${ }^{51} \mathrm{Cr}$-EDTA clearance ${ }^{16}$ was used in only two of the six studies.

The total number of patients with SCIs included in each of the six studies was relatively small: 36, 70, 116, 31, 27 and 141 patients. ${ }^{1,5,16,17,20}$ In three of the studies, nearly $100 \%$ of the patients were men ${ }^{5,6,17}$ and only 22 women (5\%) out of 421 patients were included in the six studies. In the present study, $32 \%$ of the patients were women, which is more representative of the population with SCIs.

One limitation to the present study was the relatively low number of patients $(11.7 \%)$ with a measured GFR $<60 \mathrm{ml} \mathrm{min}^{-1}$ per $1.73 \mathrm{~m}^{2}$. Future research in this area should include a larger population of SCI patients with measured GFRs $<60 \mathrm{ml} \mathrm{min}^{-1} 1.73 \mathrm{~m}^{2}$ to validate the new equation for $\mathrm{eGFR}_{\mathrm{Cys}}$.

\section{CONCLUSION}

After comparing all of the variables examined in this study, serum CysC levels are a better index of GFRs than creatinine levels or $\mathrm{eGFR}_{\mathrm{MDRD}}$. In patients with SCIs, GFRs can be estimated independent of age, sex and muscle mass using a single serum $\mathrm{Cys} C$ value. Serum levels of creatinine and $\mathrm{eGFR}_{\mathrm{MDRD}}$ can not be used to detect early decrease of renal function. Creatinine clearance determinations can be used, but such methods are often difficult and time consuming for patients to perform. 


\section{CONFLICT OF INTEREST}

The authors declare no conflict of interest

1 MacDiarmid SA, Mclntyre WJ, Anthony A, Bailey RR, Turner JG, Arnold EP. Monitoring of renal function in patients with spinal cord injury. BJU Int 2000; 85: 1014-1018.

2 Thomas L, Huber AR. Renal function-estimation of glomerular filtration rate. Clin Chem Lab Med 2006; 44: 1295-1302.

3 Perrone RD, Madias NE, Levey AS. Serum creatinine as an index of renal function: new insights into old concepts. Clin Chem 1992; 38: 1933-1953.

4 Narayanan S, Appleton HD. Creatinine: a review. Clin Chem 1980; 26: 1119-1126.

5 Chikkalingaiah KB, Grant ND, Mangold TM, Cooke CR, Wall BM. Performance of simplified modification of diet in renal disease and Cockcroft-Gault equations in patients with chronic spinal cord injury and chronic kidney disease. Am J Med Sci 2010; 339: 108-116.

6 Sepahpanah F, Burns SP, McKnight B, Yang CC. Role of creatinine clearance as a screening test in persons with spinal cord injury. Arch Phys Med Rehabil 2006; 87: 524-528.

7 Soares AA, Eyff TF, Campani RB, Ritter L, Camargo JL, Silveiro SP. Glomerular filtration rate measurement and prediction equations. Clin Chem Lab Med 2009; 47: 1023-1032.

8 Levey AS, Coresh J, Greene T, Stevens LA, Zhang Y, Hendriksen S et al. Using Standardized serum creatinine values in the modification of diet in renal disease study equation for estimating glomerular filtration rate. Ann Intern Med 2006; 145: 247-254.

9 Seronie-Vivien S, Delanaye P, Pieroni L, Mariat C, Froissart M, Cristol JP et al. Current position and future prospects. Clin Chem Lab Med 2008; 46: 1664-1686.
10 Randers E, Erlandsen EJ. Serum cystatin $C$ as an endogenous marker of the renal function-a review. Clin Chem Lab Med 1999; 37: 389-395.

11 Erlandsen EJ, Randers E, Kristensen JH. Evaluation of the Dade Behring N Latex Cystatin C assay on the Dade Behring Nephelometer II System. Scand J Clin Lab Invest 1999; 59: 1-8.

12 Brochner-Mortensen J. Current status on assessment and measurement of glomerular filtration rate. Clin Physiol 1985; 5: 1-17.

$13 \mathrm{~K} / \mathrm{DOQ}$ clinical practice guidelines for chronic kidney disease: evaluation, classification, and stratification. Am J Kidney Dis 2002; 39: S1-S266.

14 Randers E, Erlandsen EJ, Pedersen OL, Hasling C, Danielsen H. Serum cystatin C as an endogenous parameter of the renal function in patients with normal to moderately impaired kidney function. Clin Nephrol 2000; 54: 203-209.

15 Martensson A, Rustad $\mathrm{P}$, Lund $\mathrm{H}$, Ossowicki $\mathrm{H}$. Creatininium reference intervals for corrected methods. Scand J Clin Lab Invest 2004; 64: 439-441.

16 Thomassen SA, Johannesen IL, Erlandsen EJ, Abrahamsen J, Randers E. Serum cystatin $\mathrm{C}$ as a marker of the renal function in patients with spinal cord injury. Spinal Cord 2002; 40: 524-528.

17 Lee JP, Dang AT. Evaluation of methods to estimate glomerular filtration rate versus actual drug clearance in patients with chronic spinal cord injury. Spinal Cord 2011; 49: 1158-1163.

18 Stevens LA, Coresh J, Schmid $\mathrm{CH}$, Feldman HI, Froissart M, Kusek J et al. Estimating GFR using serum cystatin $C$ alone and in combination with serum creatinine: a pooled analysis of 3,418 individuals with CKD. Am J Kidney Dis 2008; 51: 395-406.

19 Tidman M, Sjostrom P, Jones I. A Comparison of GFR estimating formulae based upon s-cystatin $\mathrm{C}$ and s-creatinine and a combination of the two. Nephrol Dial Transplant 2008; 23: 154-160.

20 Jenkins MA, Brown DJ, lerino FL, Ratnaike SI. Cystatin C for estimation of glomerular filtration rate in patients with spinal cord injury. Ann Clin Biochem 2003; 40: 364-368. 